\title{
Phytochemical and pharmacological evaluation of Tragia cannabina for anti-inflammatory activity
}

\author{
Raju Venkategowda Hosahally ${ }^{1}$, Ganapaty Seru², *Prasanna Shankarrao Sutar³, Vijaya Gopalachar Joshi³, \\ Kishori Prasanna Sutar ${ }^{3}$, Asif Abdulrahiman Karigar ${ }^{3}$ \\ ${ }^{1}$ Department of Pharmacognosy, Visveswarapura Institute of Pharmaceutical Sciences, Bangalore, Karnataka, India \\ ${ }^{2}$ Department of Pharmaceutical Sciences, Andhra University, Vishakapatnam, India \\ ${ }^{3}$ Department of Pharmacognosy, Maratha Mandal's College of Pharmacy, Belgaum-590016, Karnataka, India
}

\begin{abstract}
The present study investigates the anti-inflammatory activity of methanolic and chloroform extracts of Tragia cannabina. The whole plant of Tragia cannabina was extracted with methanol and chloroform by using soxhlet apparatus. The effect of both extracts of Tragia cannabina was studied on carrageenan induced paw edema. The methanolic extract decreased the edema induced in hind paw. The percentage inhibition of paw edema was maximum with methanolic and chloroform extracts of Tragia cannabina at $300 \mathrm{mg} / \mathrm{kg}$ body weight and has showed significant antiinflammatory activity. It has been concluded that both the methanolic and chloroform extracts of Tragia cannabina showed significant anti-inflammatory activity comparable to that of reference standard Ibuprofen.
\end{abstract}

Key Words: Methanolic extract, chloroform extract, anti-inflammatory activity, carrageenan, Ibuprofen, Euphorbiaceae.

\section{INTRODUCTION}

The major screens for biological activities of plant extracts have been carried out in the search for new anticancer, antiviral and anti-inflammatory drugs (Balandrin et al., 1993). The development of the rapid screening tests now in use in industry has meant that many more plants can be evaluated for a wide range of biological activities (Neil et al., 1993). Unfortunately the results of such tests do not necessarily reach the public domain and are kept in locked industrial files (Cragg et al., 1993). There still remains an urgent need to develop new clinical drugs and this can be exemplified by the numerous diseases which result from the malfunction of the central nervous system, e.g. Alzheimers and Parkinsons disease, epilepsy, migraine, pain, schizophrenia, sleeping disorders (Jardin et al., 1980; Kingston et al., 1993). Natural products already have a proven track record for central nervous system

\footnotetext{
*Corresponding Author:

Prasanna Shankarrao Sutar, Assistant Professor

Department of Pharmacognosy

Maratha Mandal's College of Pharmacy

\#1007 opposite Police parade ground, Subash nagar

M.M.Extension, Belgaum-590016, Karnataka, India

E-mail: prs2005@rediffmail.com
}

activities, e.g. caffeine, codeine, morphine, nicotine, reserpine and it is possible that there are further such drugs still to be found from nature (Wall et al., 1993; Kinghorn et al., 1993). The Euphorbiaceae is the one of the largest family of dicotyledons, and also has significant economic importance. The family has a cosmopolitan distribution with 300 genera and about 7500 species. Tragia is one of the largest genus of Euphorbiaceae. It contains trees, shrubs (or) herbs and used as anti-inflammatory, anti-diabetic and anti oxidant. Tragia species are rich in steroids, flavonoids, alkaloids and tannins. The literature survey revealed that the methanolic extract of Tragia cannabina posses anti hyperglycemic property on Streptozotocin -Induced Diabetic rats (Vaiyapuri et al., 2007). In view of the reported medicinal properties and the presence of a various chemical constituents the author selected Tragia cannabina, to study the chemical examinations and anti-inflammatory activity (Kinghorn et al., 1993; Kirtikar et al., 2002). 


\section{MATERIALS AND METHODS}

Plant material was collected around the local area Mandya and was authenticated (RRCBI No. 3716, dated 30-03-2007) by Dr. Gajendra Rao, Survey Officer, Regional Research Institute, Bangalore. The whole plant of Tragia cannabina $(1.2 \mathrm{~kg})$ were air dried, powdered in willy mill and extracted successively with petroleum ether, chloroform and methanol (3lit $\times 2$ each) and concentrated under vacuum to the corresponding residues:

Petroleum ether extract residue $-8 \mathrm{~g}$

Chloroform extract residue $-9 g$

Methanolic extract residue $-15 \mathrm{~g}$

The Chloroform and Methanolic extracts of $T$. cannabina were evaluated for anti-inflammatory activity using Ibuprofen $(10 \mathrm{mg} / \mathrm{kg})$ as reference standard. The activity was tested on carrageenan induced paw oedema in rats.

\section{Preliminary Phytochemical Evaluation of Tragia cannabina}

The whole plant of Tragia cannabina $(1 \mathrm{~kg})$ was extracted by soxhlet extractor with methanol (3 liters) and concentrated under vacuum to get the residue of $15 \mathrm{gm}$. The residue was dissolved in methanol and this dark brown residue was examined on thin layer chromatography, which showed 3 prominent spots in Petroleum ether: benzene (1:1) solvent system with Rf values $0.6,0.4$ and 0.1 (Wagner et al., 2002).

The methanolic extract showed 3 spots with chloroform: benzene (1:1) with Rf values $0.47,0.16$ and 0.26 and showed two prominent spots in Ethyl acetate: formic acid: glacial acetic acid: water (100:11:11:27) solvent system with Rf values 0.75, and 0.76 .

Then the extract was tested for various chemical constituents like steroids, alkaloids, tannins flavonoids, carbohydrates and glycosides.

\section{Test for Tannins}

- $0.1 \mathrm{gm}$ of the chloroform extract was dissolved in methanol in a test tube and 2 drops of ferric chloride was added. An olive green color appeared which indicated the presence of tannins.

- $0.1 \mathrm{gm}$ of the methanolic extract was dissolved in methanol in a test tube and 2 drops of ferric chloride was added. An olive green color ap- peared which indicated the presence of tannins (Kokate, 1994).

\section{Test for Sterols and Triterpenoids}

- $0.1 \mathrm{gm}$ of the chloroform extract was dissolved in chloroform in a test tube and 2 drops of acetic anhydride was added. It was boiled and 1 drop of concentrated sulphuric acid was added after cooling. A green color appeared which indicated the presence of sterols.

- $0.1 \mathrm{gm}$ of the chloroform extract was dissolved in chloroform in a test tube and 2 drops of concentrated sulphuric acid was added. It was allowed to stand for some time until red color appeared, which indicated the presence of sterols (Peach, 1995).

\section{Tests for Flavonoids}

- $0.1 \mathrm{gm}$ of the chloroform extract was dissolved in methanol in a test tube with few fragments of magnesium ribbons and 1 drop of hydrochloric acid. A crimson red color appeared which indicated the presence of flavonoids.

- $0.1 \mathrm{gm}$ of the chloroform extract was dissolved in methanol in a test tube with $0.5 \mathrm{~g}$ of zinc dust and $1 \mathrm{ml}$ of concentrated hydrochloric acid. A red color appeared which indicated presence of flavonoids (Pulok, 2002).

\section{Tests for Alkaloids}

- $0.1 \mathrm{gm}$ of the methanolic extract was dissolved in methanol in a test tube. $1 \mathrm{ml}$ of potassium bismuth iodide was added. A reddish brown precipitate appeared which indicated the presence of alkaloids.

- $0.1 \mathrm{gm}$ of the methanolic extract was dissolved in methanol in a test tube and $1 \mathrm{ml}$ of saturated picric acid was added. A yellow precipitate appeared which indicated the presence of alkaloids (Brain, 1975).

\section{Test for Carbohydrates}

- $0.1 \mathrm{gm}$ of the methanolic extract was dissolved in methanol in a test tube and $1 \mathrm{ml}$ of alcoholic $\propto$-naphthol and $0.2 \mathrm{ml}$ concentrated sulphuric acid were added. A purple to violet color ring was not appeared which indicated the absence of carbohydrates.

- $0.1 \mathrm{gm}$ of the methanolic extract was dissolved in methanol in a test tube and $1 \mathrm{ml}$ of Benedict's 
Table 1: Anti inflammatory activity of Tragia cannabina extracts on carrageenan induced paw oedema in rats.

\begin{tabular}{|c|c|c|c|c|c|c|c|c|}
\hline \multirow{2}{*}{$\begin{array}{l}\text { Sl. } \\
\text { No. }\end{array}$} & \multirow{2}{*}{ Treatment } & \multirow{2}{*}{ Dose } & \multicolumn{6}{|c|}{ Volume of mercury displaced in $\mathrm{ml}$ at various time intervals in hours } \\
\hline & & & 0 & 1 & 2 & 3 & 4 & 5 \\
\hline 1 & Control & $0.1 \mathrm{ml} \mathrm{1 \%} \mathrm{W/V}$ & $0.36 \pm 0.01$ & $0.54 \pm 0.02$ & $0.66 \pm 0.01$ & $0.78 \pm 0.04$ & $0.86 \pm 0.03$ & $0.88 \pm 0.05$ \\
\hline 2 & Ibuprofen & $10 \mathrm{mg} / \mathrm{kg}$ & $0.36 \pm 0.01$ & $0.37 \pm 0.02^{* * *}$ & $0.38 \pm 0.01^{* * *}$ & $0.38 \pm 0.03^{* * *}$ & $0.39 \pm 0.01^{* * *}$ & $0.39 \pm 0.04^{* * *}$ \\
\hline 3 & Chloroform Extract & $100 \mathrm{mg} / \mathrm{kg}$ & $0.36 \pm 0.01$ & $0.52 \pm 0.01^{*}$ & $0.62 \pm 0.02 *$ & $0.72 \pm^{*} 0.01$ & $0.76 \pm 0.01^{*}$ & $0.77 \pm 0.01^{*}$ \\
\hline 4 & Chloroform Extract & $300 \mathrm{mg} / \mathrm{kg}$ & $0.36 \pm 0.01^{*}$ & $0.51 \pm 0.03^{*}$ & $0.62 \pm 0.05^{*}$ & $0.70 \pm^{* *} 0.04$ & $0.72 \pm 0.03^{* *}$ & $0.73 \pm 0.02^{* *}$ \\
\hline 5 & Methanolic Extract & $100 \mathrm{mg} / \mathrm{kg}$ & $0.36 \pm 0.01$ & $0.52 \pm 0.01^{*}$ & $0.62 \pm 0.02^{*}$ & $0.78 \pm 0.01^{*}$ & $0.72 \pm 0.03^{*}$ & $0.72 \pm 0.04^{*}$ \\
\hline 6 & Methanolic Extract & $300 \mathrm{mg} / \mathrm{kg}$ & $0.36 \pm 0.01$ & $0.47 \pm 0.02^{* *}$ & $0.50 \pm 0.05^{* *}$ & $0.52 \pm 0.03^{* *}$ & $0.54 \pm 0.01^{* * *}$ & $0.55 \pm 0.04^{* * *}$ \\
\hline
\end{tabular}

reagent (alkaline sodium cupric citrate) was added. The solution was boiled in water bath. No brick red precipitate appeared which, indicated the absence of carbohydrates (Jean, 1999).

\section{Test of Glycosides}

$200 \mathrm{mg}$ of methanolic extract was dissolved in methanol in a test tube and boiled with $5 \mathrm{ml}$ of dilute Sulphuric acid for 2 minutes. It was filtered and the filtrate was neutralized with $5 \%$ sodium hydroxide. $0.1 \mathrm{ml}$ Fehling's solution A and B were added to the solution and was heated on a water bath for 2 minutes. No brick red color was formed which indicated the absence of glycosides (Khandelwal, 2002).

Chemical Tests and thin layer chromatographic studies of $T$. cannabina revealed the presence of tannins, flavonoids and alkaloids.

\section{Evaluation of Anti-Inflammatory Activity}

In this method, $0.5 \mathrm{mg}$ of $1 \% \mathrm{w} / \mathrm{v}$ carrageenan in saline was injected into the footpad of rat subcutaneously, to induce oedema. The thickness of paw was measured before and after carrageenan injection at hourly intervals up to $5 \mathrm{hrs}$ with plethysmometer (Vogel, 2002). Albino rats of either sex weighing between 200-250g were selected, housed under standard temperature $\left(23 \pm 1^{\circ} \mathrm{C}\right)$ and divided into 6 groups of six animals each.

Group I served with normal saline ( $5 \mathrm{ml} / \mathrm{kg}$, p.o).

Group II was given Ibuprofen $(10 \mathrm{mg} / \mathrm{kg})$ remaining groups received $100 \mathrm{mg}$ and $300 \mathrm{mg}$ of methanolic and chloroform extract of Tragia cannabina $0.1 \mathrm{ml}$ of carragenan $(1 \%)$ in normal saline $(0.9 \%)$ was injected into sub-planter area of right hind paw for all the groups. All the drugs were administered orally one hour prior to carragenan injection. After the administration of carrageenan, volume of rats paw was measured at 0 hour and at hourly intervals up to $5^{\text {th }}$ hour by volume displacement method, using plethesmometer.

The anti-inflammatory activity was expressed as:

Percentage inhibition of oedema $=100-\left[1-\left(\frac{V t}{V c}\right)\right]$ where $\mathrm{Vt}$ and $\mathrm{Vc}$ are volume of carrageenan-injected paws of drug treated group and control group respectively. The results were tabulated and data is statistically analyzed using one-way ANOVA followed by Dunnet's test and results were presented in the table 1 and 2.

Table 2: Percentage inhibition of Tragia cannabina extracts on carrageenan induced paw oedema in rats.

\begin{tabular}{|c|c|c|c|c|c|c|c|c|}
\hline \multirow{2}{*}{$\begin{array}{l}\text { Sl. } \\
\text { No. }\end{array}$} & \multirow{2}{*}{ Treatment } & \multirow{2}{*}{ Dose } & \multicolumn{6}{|c|}{ \% Inhibition at various time intervals } \\
\hline & & & 0 & 1 & 2 & 3 & 4 & 5 \\
\hline 1 & Control & $0.1 \mathrm{ml} \mathrm{1 \%} \mathrm{W/V}$ & 00 & 00 & 00 & 00 & 00 & 00 \\
\hline 2 & Ibuprofen & $10 \mathrm{mg} / \mathrm{kg}$ & 00 & 31.44 & 42.43 & 51.29 & 54.66 & 55.69 \\
\hline 3 & Methanolic Extract & $100 \mathrm{mg} / \mathrm{kg}$ & 00 & 3.71 & 6.07 & 12.83 & 16.28 & 17.05 \\
\hline 4 & Methanolic Extract & $300 \mathrm{mg} / \mathrm{kg}$ & 00 & 12.97 & 24.43 & 33.33 & 37.21 & 37.5 \\
\hline 5 & Chloroform Extract & $100 \mathrm{mg} / \mathrm{kg}$ & 00 & 3.71 & 4.55 & 7.7 & 11.63 & 12.5 \\
\hline 6 & Chloroform Extract & $300 \mathrm{mg} / \mathrm{kg}$ & 00 & 5.5 & 6.07 & 10.26 & 16.28 & 17.05 \\
\hline
\end{tabular}




\section{RESULTS AND DISCUSSION}

Chloroform extract of Tragia cannabina at dose level $100 \mathrm{mg} / \mathrm{kg}$ and $300 \mathrm{mg} / \mathrm{kg}$, the percentage inhibitions of paw volume were found to be at $1^{\text {st }}$ hour is $3.71 \%$, $2^{\text {nd }}$ hour is $4.55 \%$, 3rd hour is $7.7 \%$, $4^{\text {th }}$ hour is 11.63 $\%$ and $5^{\text {th }}$ hour is $12.5 \%$. The $\%$ inhibition of paw oedema was more at $5^{\text {th }}$ hour and at $1^{\text {st }}$ hour is $5.5 \%$, $2^{\text {nd }}$ hour is $6.07 \%$, 3rd hour is $10.26 \%$, $4^{\text {th }}$ hour is $16.28 \%$ and $5^{\text {th }}$ hour is $17.05 \%$. The $\%$ inhibition of paw oedema was more at $5^{\text {th }}$ hour respectively.

Methanolic extract of $T$. cannabina at a dose level of $100 \mathrm{mg} / \mathrm{kg}$ and $300 \mathrm{mg} / \mathrm{kg}$ the percentage inhibitions were found to be $1^{\text {st }}$ hour is $3.71 \%, 2^{\text {nd }}$ hour is $6.7 \%$, 3 rd hour is $12.83 \%$, $4^{\text {th }}$ hour is $16.28 \%$ and $5^{\text {th }}$ hour is $17.05 \%$. The percentage inhibition of paw at $1^{\text {st }}$ hour is $12.97 \%, 2^{\text {nd }}$ hour is $24.43 \%, 3^{\text {rd }}$ hour is $33.33 \%, 4^{\text {th }}$ hour is $37.21 \%$ and $5^{\text {th }}$ hour $37.5 \%$. The percentage inhibition of paw oedema was maximum at $5^{\text {th }}$ hour. Chloroform and methanolic extracts showed good anti inflammatory activity comparable to standard. The chloroform and methanolic extracts showed significant anti-inflammatory activity comparable to that of reference standard Ibuprofen.

Carrageenan induced oedema is mediated by release of histamine and 5HT followed by the prostaglandin kinin and have been frequently used to assess the anti-inflammatory effects of natural products. The chloroform and methanolic extracts may act by reducing the effect of inflammatory mediators.

\section{CONCLUSION}

It was demonstrated by animal model studies that methanolic and chloroform extracts of Tragia cannabina reduced inflammation at a dose of $100 \mathrm{mg} / \mathrm{kg}$ body weight and $300 \mathrm{mg} / \mathrm{kg}$ body weight. Further this study indicates chloroform and methanolic extracts showed significant anti-inflammatory activity comparable to that of reference standard.

\section{ACKNOWLEDGEMENT}

Authors are thankful to the Rajiv Gandhi University of Health Sciences Bangalore, Karnataka, India and Visveswarapura Institute of Pharmaceutical Sciences, Bangalore Karnataka, India for providing facilities to carry out the research work.

\section{REFERENCES}

Balandrin, M.F., Kinghorn, A.D. and Farnsworth, N.R. (1993). Human Medicinal agents from Plants, ACS Symposium Series 534, Washington; DC, pp. 2.

Brain, K.R., and Turner, T.D. (1975). The Practical Evaluation of Phytopharmaceuticals, 155.

Cragg, G.M., Boyd, M.R., Cardellina, J.H., Grever, M. (1993). Human Medicinal Agents from Plants, ACS Symposium Series 534, Washington, DC, pp. 80.

Jardine, I. (1980). Anticancer Agents Based on Natural Product Models., Academic press, New York, pp. 319.

Jean Brunteon. (1999). Phytochemistry of Medicinal plants, pp. 225-369.

Khandelwal, M. (1995). Practical Pharmacognosy. Nirali Publications, pp. 140-143.

Kinghorn, A.D and Balandrin, M.F. (1993). Human Medicinal Agents from Plants, ACS Symposium Series 534, Washington; DC, pp. 48.

Kingston, D.G.I. (1993). Human Medicinal Agents from Plants, ACS Symposium Series 534, Washington, DC, pp. 48 .

Kirtikar K.R., Basu B.D. (2002). Indian Medicinal Plants, 3 , 2190-2191.

Kokate C.K., Purohit A.P., Gokhale S.B. (1994) “Practical Pharmacognosy", 2, 54-60.

Neill, M.O., Lewis, J.A. (1993). Human Medicinal Agents from Plants, ACS Symposium Series 534, Washington; DC, pp. 48.

Peach, K., and Tracey, M.,V.,(1995). Modern methods of Plant analysis. 3, pp. 467-478.

Pulok, K., Mukherjee, (2002). Quality control of Herbal Drugs, pp. 540-542 .

Vaiyapuri, S., Akalanka, D., B.,Jayakar, (2007). Antihyperglycemic propertiy of Tragia cannabina in Streptozocin induced diabetic rats. Journal of Medicinal Food. 10(2): 361-365. [DOI] PMid:17651075

Vogel, H.G., (2002), Drug discovery and evaluation, pp. 755769. [DOI]

Wagner, H., Bladet, S., Zgainski, E.M., (1994). Plant drug analysis- A TLC Atlas, Springer Verlag Berlin Heidelberg New York, pp. 163-192.

Wall, M.,E., and Wani, M.,C., (1993). Human Medicinal Agents from Plants, ACS Symposium Series 534, Washington; DC, pp. 48 . 